\title{
Migration and Transformation Behaviors of Neurotoxin BMAA along Food Chains in a Diatom-dominated Marine Ecosystem in China
}

\author{
Chao Wang ${ }^{1}$, Chen Yan ${ }^{1}$, Jiangbing Qiu ${ }^{1}$, Chao Liu ${ }^{1}$, Yeju Yan ${ }^{1}$, Ying $\mathrm{Ji}^{1}$, Guixiang \\ Wang ${ }^{1}$, Hongju Chen ${ }^{1}$, Yang $\mathrm{Li}^{2}$, Sandra Banack ${ }^{3}$, and Aifeng Li ${ }^{1}$ \\ ${ }^{1}$ Ocean University of China \\ ${ }^{2}$ South China Normal University \\ ${ }^{3}$ The Institute for Ethnomedicine
}

June 15, 2020

\begin{abstract}
Neurotoxin $\beta$-N-methylamino-L-alanine (BMAA) produced by cyanobacteria and microalgae has been concerned by scientists due to its toxicity to human motoneurons. The source and environmental behaviors of BMAA in marine ecosystem are important to understand its risk to human health. Here a diatoms-dominated marine ecosystem in Jiaozhou Bay, China, was investigated for BMAA contamination in phytoplankton, zooplankton, and marine animals, during four seasons in 2019. Results showed that BMAA was migrated and biomagnified along the food chains from phytoplankton to higher trophic organisms, in which the trophic magnification factors (TMF) for zooplankton, bivalve mollusks, carnivorous crustacea and saprophytic gastropod mollusks were approximately 4.58, 30.1, 42.5, and 74.4, respectively. An isomer of BMAA, $\beta$-aminomethyl-L-alanine (BAMA), was ubiquitous in phytoplankton samples and its content ratios to BMAA looks gradually decreased with increasing trophic levels. A total of 56 diatom strains (Pseudo-nitzschia spp., Thalassiosira spp., Chaetoceros spp., Planktoniella spp., Minidiscus spp.) were isolated from the Chinese coast and cultured in the laboratory, among which 21 strains produced BMAA mainly presented in the precipitated bound fraction ranging from 0.11 to $3.95 \mu \mathrm{g}$ g-1 dry weight. BMAA was firstly detected in both Pseudo-nitzschia and Planktoniella genera in this study. Only 2,4-diaminobutyric acid (DAB) but not BMAA or BAMA was detected in seven symbiotic bacteria isolated from the gut of Neverita didyma, which further proves that the benthic vector of BMAA, N. didyma, accumulated BMAA through food chains. These findings demonstrated that the coastal residents have a risk to accumulate BMAA by consumption of seafood products.
\end{abstract}

\section{Significance Statement}

The biomagnification of BMAA along food chains was synthetically investigated and discussed in the diatomdominated marine ecosystem. The ubiquity of BAMA, an isomer of BMAA, was confirmed in the phytoplankton samples using the pre-column derivatization method. Results showed that diatoms are the source of BMAA in marine ecosystem because 21 of 56 diatom strains contained this neurotoxin. No BMAA was detected in the isolated bacterial strains from the gut of the typical vector of BMAA,Neverita didyma, which further confirmed that the toxin BMAA was transferred and accumulated along food chains. All these findings improve our understanding for the environmental behavior and risk to human health of the neurotoxin BMAA.

\section{Introduction}

The neurotoxin $\beta-N$-methylamino- $L$-alanine (BMAA) (Supplementary Fig. 1) was hypothesized as an environmental factor responsible to the endemic amyotrophic lateral sclerosis-parkinsonism dementia complex 
(ALS-PDC) in Guam and other globally sporadic neurodegenerative diseases including ALS and Alzheimer's disease $(\mathrm{AD})^{1-4}$. Symbiotic cyanobacteria in the coralloid roots of cycad trees were demonstrated as the producer of BMAA in Guam ${ }^{5}$, which was followed by several studies showing positive detection of BMAA in diverse free-living cyanobacteria in seawater or freshwater environments ${ }^{6-14}$. Later some eukaryotic organisms such as dinoflagellates ${ }^{15,16}$ and diatoms ${ }^{17-19}$ were reported to produce this neurotoxin.

Significant bioaccumulation and biomagnification of BMAA were reported in zooplankton and various vertebrates (fish) and invertebrates (mussels, oysters) in Baltic Sea dominated by massive surface cyanobacterial blooms ${ }^{20}$, following the report on BMAA biomagnification in the Guam ecosystem ${ }^{5}$. Varied concentrations of BMAA (nd to $\sim 7000 \mu \mathrm{g} \mathrm{g}^{-1}$ ) were detected in diverse resident animals suffering from cyanobacterial blooms in the South Florida aquatic ecosystem ${ }^{6}$. Six freshwater aquaculture products in different trophic levels also contained BMAA in the Taihu Lake Basin with chronic pollution of cyanobacterial blooms ${ }^{21}$. The feeding patterns (plankton-benthivorous) and increased age of fish leading to a higher concentration of BMAA was also found in the Lake Finjasjön in southern Sweden ${ }^{22}$. Muscle, liver, and brain tissue samples of a huge carp from the Lake Mascoma, as well as filtered aerosol samples contained BMAA ${ }^{23}$. Additionally, positive detection of BMAA was reported in mussels and other mollusks in French coasts ${ }^{24-26}$, in Sweden ${ }^{27,28}$, as well as in diverse filter-feeding mollusks or benthic gastropod in China ${ }^{29,30}$. Expectedly higher concentrations of BMAA [144 $1836 \mu \mathrm{g} \mathrm{g}^{-1}$ wet weight (WW)] were detected in fin samples of sharks from South Florida ${ }^{31}$. These findings of BMAA in aquatic animals at different trophic levels demonstrate an exposure risk to BMAA through a diet of aquatic products.

The detection of BMAA in the brain tissues of both ALS-PDC patients from Guam ${ }^{4}$ and sporadic AD or ALS patients from the United States ${ }^{32}$ further support the linkage between BMAA and neurodegenerative diseases. Additionally, BMAA was shown to be mis-incorporated into proteins to replace L-serine ${ }^{33}$ and following incorporation could slowly release this toxin as an endogenous source ${ }^{34}$. Vervets (Chlorocebus sabaeus ) fed a low-dose of BMAA over an extended period of time in fruit developed neurofibrillary tangles (NFT) and sparse $\beta$-amyloid deposits in the brain in contrast to control animals that were free from these protein deposits, which indicated that chronic exposure to the environmental BMAA can trigger neurodegeneration in vulnerable individuals ${ }^{35}$. Mathematical models of BMAA insertion into proteins suggest that the replacement of BMAA for L-serine in the SOD1 or $\beta$-amyloid protein could play a role in neurodegeneration ${ }^{36}$.

Although the presence of BMAA in cyanobacterial samples is consistent across many studies, the quantitation of BMAA in cyanobacterial samples vary widely and reflects different methods on different samples ${ }^{37-42}$. Interestingly, no BMAA was detected from cyanobacteria isolated from Chinese freshwater environments using LC-HILIC-MS/MS method ${ }^{38}$, but BMAA was detected in diverse mollusks and gastropod from marine ecosystem in China using the same method ${ }^{29,30}$. A recent review article described marine bivalves as having higher concentrations of BMAA, far more than most fish muscles, but with an exception for shark cartilage, which hinted that the source of BMAA in aquatic ecosystem requires further investigations ${ }^{43}$. In addition, the hypothesis of a causal relationship between BMAA and neurodegenerative disease relationship has also been criticized but without primary data and using selective sources only ${ }^{44}$. It is clear that additional studies would benefit this field. In the marine ecosystem in China, the absence of BMAA detection in cyanobacterial samples but ubiquity in diverse marine animals ${ }^{30,38}$ suggests that this may be a good study case to further examine biomagnification of BMAA.

The Jiaozhou Bay located in the Yellow Sea of China was selected as the survey area in the present study. Phytoplankton, zooplankton, mollusks, and crustacea samples were collected during four different seasons and analyzed for BMAA and its isomers $\beta$-aminomethyl- $L$-alanine (BAMA), 2,4-diaminobutyric acid (DAB) and $N$-(2-aminoethyl) glycine (AEG) in marine organisms of different trophic levels using an LC-MS/MS method. An additional 56 strains (belong to 5 genera) of diatoms isolated from Chinese seawater were cultured and scanned for these compounds. Bioaccumulation and magnification of BMAA in different marine organisms at different trophic levels in the Jiaozhou Bay were discussed in the present study.

\section{Results}


BMAA and its isomers in the field phytoplankton and zooplankton. The observed results for the field phytoplankton samples showed that diatoms dominated the phytoplankton community in Jiaozhou Bay, China (Supplementary Fig. 2). The dominant species in phytoplankton and zooplankton samples in different seasons are listed in Supplementary Table 1. Concentrations of total soluble BMAA in these samples were determined by LC-MS/MS (Fig. 2, Supplementary Table 2). Results showed that concentrations of BMAA varied in plankton samples in different seasons and were basically higher in zooplankton than phytoplankton except for January. Interestingly, BMAA concentrations in phytoplankton were higher than that in zooplankton in some sampling stations in January. The highest concentration of BMAA in all seasons occurred in the zooplankton at station C3 in January and Oikopleura dioica dominated the zooplankton community at this station. Average concentration of BMAA in phytoplankton samples collected in January $\left(\sim 0.47 \mu \mathrm{g} \mathrm{g}^{-1} \mathrm{DW}\right)$ was significantly higher than that in other seasons (March $\sim 0.03 \mu \mathrm{g} \mathrm{g}{ }^{-1} \mathrm{DW}$, June ${ }^{\sim} 0.02$ $\mu \mathrm{g} \mathrm{\textrm {g } ^ { - 1 }} \mathrm{DW}$, and September $\left.\sim 0.05 \mu \mathrm{g} \mathrm{g}^{-1} \mathrm{DW}\right)$. However, average concentrations of BMAA in zooplankton were similar in samples collected in January $\left(\sim 0.44 \mu \mathrm{g} \mathrm{g}{ }^{-1} \mathrm{DW}\right)$ and June $\left({ }^{\sim} 0.43 \mu \mathrm{g} \mathrm{g} \mathrm{g}^{-1} \mathrm{DW}\right)$, which was followed by March $\left({ }^{\sim} 0.11 \mu \mathrm{g} \mathrm{g} \mathrm{g}^{-1} \mathrm{DW}\right)$ and September $\left({ }^{\sim} 0.23 \mu \mathrm{g} \mathrm{g} \mathrm{g}^{-1} \mathrm{DW}\right)$ (Supplementary Fig. 3).

An isomer of BMAA, BAMA, was widely detected in the field plankton samples collected in the four seasons with a high detection rate $97.9 \%$ (47/48). All samples were analyzed early by ZIC-HILIC column, then both BMAA and BAMA were separated and confirmed by $\mathrm{C} 18$ column using AQC-derivatization method (Supplementary Fig. 1). Another isomer of BMAA, DAB, was also commonly detected in plankton samples in this study, and the detection rates of DAB in phytoplankton and zooplankton were $83.3 \%(40 / 48)$ and $75 \%$ (36/48), respectively. Concentrations of DAB in phytoplankton and zooplankton samples varied in the ranges of $0.01 \sim 0.48 \mu \mathrm{g} \mathrm{g}^{-1} \mathrm{DW}$ and $0.1 \sim^{\sim} 5.73 \mu \mathrm{g} \mathrm{g}^{-1} \mathrm{DW}$, respectively, of which the average concentration of DAB in zooplankton $\left(0.43 \mu \mathrm{g} \mathrm{g}^{-1} \mathrm{DW}\right)$ was higher than that in phytoplankton $\left(0.05 \mu \mathrm{g} \mathrm{g}^{-1} \mathrm{DW}\right)$. Comparing the detection rates of BAMA, DAB, and BMAA in plankton samples showed that BAMA is more universal than other compounds, in which the detection rates ranked in an order of BAMA $(97.9 \%)>$ DAB $(83.3 \%)>$ BMAA $(79.2 \%)$ and BAMA $(100 \%)>$ BMAA $(95.8 \%)>$ DAB $(75.0 \%)$ in phytoplankton and zooplankton samples, respectively. No AEG was detected in any plankton samples.

BMAA and its isomers in mollusk and crustacea animals. Bivalve and gastropod mollusks and crustacea animals including Portunus trituberculatus, Oratosquilla oratoria and Penaeus chinensis were collected in four different seasons (Supplementary Table 3). Quantity of total soluble BMAA in these samples was determined by two different LC-MS/MS methods and characterized by wet weight (WW) (Supplementary Table 4). BMAA was commonly detected in bivalve mollusks including Atrina pectinate, Chlamys farreri ,Ruditapes philippinarum, Mytilus galloprovincialis ,Sinonovacula constricta , Crassostrea sp., Arca inflata, and Scapharca kagoshimensis . The larger individuals of Atrina pectinata contained higher concentrations of BMAA than other bivalves, with an average BMAA concentration of $2.50 \mu \mathrm{g} \mathrm{g}^{-1} \mathrm{WW}$. Average concentrations of BMAA inChlamys farreri and Scapharca kagoshimensis were 1.17 and $0.94 \mu \mathrm{g}$ $\mathrm{g}^{-1} \mathrm{WW}$, respectively, which were above the average levels of BMAA in bivalve mollusks $\left(0.84 \mu \mathrm{g} \mathrm{g}^{-1} \mathrm{WW}\right)$. Obviously, the range of concentrations $\left(0.11^{\sim} 4.29 \mu \mathrm{g} \mathrm{g} \mathrm{g}^{-1} \mathrm{WW}\right)$ varied in different gastropod mollusks including Neverita didyma ,Glossaulax reiniana, Rapana venosa, Chlorostoma rustica, Planaxis sulcatus, Abalone sp., due to different dietary habits. The highest concentration BMAA was detected in $N$. didyma at 4.29 $\mu \mathrm{g} \mathrm{g}^{-1} \mathrm{WW}$. The ranges of BMAA concentrations in marine animals were shown in Fig. 3. Totally the BMAA concentrations gradually decreased in the order of gastropod, crustacea and bivalves. However, it is remarkable that the concentration of BMAA accumulated in gastropod mollusks in March because some gastropod mollusks collected in this month were in the infancy life stage.

Another isomer of BMAA, DAB, was detected in all mollusk samples, and the concentrations of DAB in bivalve and gastropod mollusks varied in the ranges of $0.16^{\sim} 1.13 \mu \mathrm{g} \mathrm{g}^{-1} \mathrm{WW}$ and $0.06 \sim 1.45 \mu \mathrm{g} \mathrm{g}^{-1} \mathrm{WW}$, respectively. The detection rate of $\mathrm{DAB}$ was $89.5 \%$ (17/19) in arthropods with concentration ranging from 0.02 to $0.99 \mu \mathrm{g} \mathrm{g}^{-1} \mathrm{WW}$. The detection rates of BMAA and its isomers BAMA and DAB in mollusks were $100 \%$, while in arthropods, BMAA $(94.7 \%)>$ DAB $(89.5 \%)>$ BAMA $(84.2 \%)$. No AEG was detected in any animal samples. 
BMAA and its isomers inthe cultures of isolated diatom strains. A total of 56 strains of diatoms attaching to five genera including Pseudo-nitzschia, Chaetoceros, Thalassiosira, Planktoniella andMinidiscus , were cultured and analyzed for total soluble BMAA and precipitated bound BMAA. Concentrations of BMAA in diatom strains are shown in Supplementary Table 5. The neurotoxin BMAA detected in diatoms was mainly in the form of precipitated-bound (19/21), and only $5 / 21$ strains contained total soluble BMAA, in which only Thalassiosira minima, Thalassiosira allenii and Thalassiosira gravida contained both forms of BMAA. The concentrations of BMAA decreased in order of four genera including Thalassiosira, Pseudo-nitzschia, Chaetoceros, and Planktoniella (Fig. 4).

The detection rate of total soluble DAB was $83.9 \%$ (47/56) in the 56 strains of diatom cultures with the concentration ranging from 0.24 to $407.0 \mu \mathrm{g} \mathrm{g} \mathrm{g}^{-1} \mathrm{DW}$, while the detection rate of precipitated bound DAB was $44.6 \%$ (25/56) with concentration ranging from 0.02 to $13.42 \mu \mathrm{g} \mathrm{g}^{-1} \mathrm{DW}$ (Supplementary Table 5). Among the 56 cultures of diatom strains, Pseudo-nitzschia americana had the highest DAB production ability of $407.0 \mu \mathrm{g} \mathrm{g}^{-1} \mathrm{DW}$. Comparing the average concentrations of DAB in diatoms, these diatoms ranked in an order of Pseudo-nitzschia $\left(37.4 \mu \mathrm{g} \mathrm{g}^{-1} \mathrm{DW}\right)>$ Chaetoceros $\left(8.96 \mu \mathrm{g} \mathrm{g}^{-1} \mathrm{DW}\right)>$ Thalassiosira $\left(5.75 \mu \mathrm{g} \mathrm{g}^{-1} \mathrm{DW}\right)$ $>\operatorname{Minidiscua}\left(0.68 \mu \mathrm{g} \mathrm{g}^{-1} \mathrm{DW}\right)>$ Planktoniella $\left(0.27 \mu \mathrm{g} \mathrm{g}^{-1} \mathrm{DW}\right)$. No AEG was detected in any diatom cultures.

Only DAB detected in symbiotic bacteria isolated from the gut of $N$. didyma. A total of 7 strains of symbiotic bacteria were isolated and identified from the gut of $N$. didyma in the laboratory. The biological phylogenetic tree of these bacteria is shown in Fig. 5. Analytical results showed that these symbiotic bacteria did not produce BMAA or BAMA, under these experimental conditions, but DAB was detected in all strains. Interestingly there are also some unknown compounds suspected as analogues of DAB because they have the same product ions but different retention times.

\section{Discussion}

Biomagnification of BMAA along food chains was synthetically demonstrated in the diatoms-dominated marine ecosystem. The concentration of BMAA accumulated in zooplankton was generally higher than that in phytoplankton (Fig. 2), and only in January the average level of BMAA in zooplankton was slightly lower than that in phytoplankton (Supplementary Fig. 3). We note that the average concentration of BMAA in phytoplankton was much higher in January than that in other seasons. The lowest density of phytoplankton $(>20 \mu \mathrm{m})$ and the highest percent of diatoms $(99.9 \%)$ also occurred in January. Inversely, the lowest percent $(87.2 \%)$ of diatom in phytoplankton net samples occurred in June, meanwhile the average concentration of BMAA was the lowest in four seasons, which hints that the concentration of BMAA in phytoplankton was positively related to diatoms. The diatom Bacillaria paxillifera was the dominant species only in January, but it has not been reported as a producer of BMAA in the previous studies ${ }^{17-19}$. Similarly, high average concentrations of BMAA accumulated in zooplankton in January and June, which may be related to the feeding behavior of zooplankton. Only the zooplanktonOikopleura dioica predominated in the zooplankton community as the dominant species in both January and June (Supplementary Table 1). The zooplankton $O$. dioicacreates a mucus net "house" for capturing phytoplankton during feeding. Water is pumped through this house and phytoplankton are filtered out of the water and then transferred into the mouth. We suggest that this feeding method would result in an accumulation of BMAA by filtering large amounts of diatoms, while Calanus sinicus and Acartia pacificaare omnivorous, primarily feeding on phytoplankton but also consuming rotifers, ciliates, and their own eggs. Furthermore, Noctiluca scientillans is a heterotroph, primarily engulfing fish eggs, bacteria, in addition to plankton, diatoms and dinoflagellates. Therefore, the feeding habit of zooplankton and the species composition of phytoplankton are important factors for the accumulation of BMAA in zooplankton populations.

The average concentration of BMAA in phytoplankton and zooplankton net samples at all sampling stations in four seasons were 0.14 and $0.30 \mu \mathrm{g} \mathrm{g}^{-1} \mathrm{DW}$, respectively. Compared across different sampling stations, the highest trophic magnification factor (TMF) between phytoplankton and zooplankton trophic levels are shown in Supplementary Fig. 4. The TMF values of BMAA ranged from 0.45 to 11.82 in most of sampling stations except for $\mathrm{C} 1$ station in all seasons, with an average value 4.58 . The highest value occurred at the 
sampling station C3 in September (11.82), and A3, A5, B2, D6 and D7 stations had relatively low TMF values $\left(0^{\sim} 2\right)$. Compared across different seasons, the highest TMF values for BMAA occurred in different sampling stations was in September (8.50), followed by June (3.98) and January (1.13). In a previous study, the concentration of BMAA in cyanobacteria-enriched samples collected from Baltic Sea ranged from 0.001 to $0.015 \mu \mathrm{g} \mathrm{g}^{-1} \mathrm{DW}$, and zooplankton-enriched fraction contained 6-fold higher on average than the cyanobacterial samples ${ }^{20}$, of which the TMF is in the range of our study from phytoplankton to zooplankton (1.13 8.50). For another case, average BMAA concentrations were 4.12, 3.21, 3.76, and $6.05 \mu \mathrm{g} \mathrm{g}{ }^{-1} \mathrm{DW}$ in cyanobacteria, mollusks, crustaceans and various fish species, respectively, and the TMF values were below 1.5 along food chains in Gonghu Bay of Lake Taihu, China ${ }^{46}$. A relatively low biomagnification of BMAA, trophic magnification factor $\sim 1.20$, was also found in six freshwater aquaculture products from Taihu Lake Basin in China ${ }^{21}$. Comparatively, Jiaozhou Bay showed a relatively high biomagnification along food chains from diatom-dominated phytoplankton.

In order to assess the risk of human exposure to BMAA, marine animals including filter-feeding bivalve mollusks, carnivorous crustacea, and saprophytic gastropod mollusks, were collected together to monitor BMAA accumulation. Results showed that BMAA was universally detected in marine animals collected during the whole year. Average concentrations of BMAA accumulated in bivalve, crustacea and gastropod mollusks were $0.84,1.19$, and $2.08 \mu \mathrm{g} \mathrm{g}^{-1} \mathrm{WW}$, respectively, corresponding to $4.22,5.95$, and $10.42 \mu \mathrm{g} \mathrm{g}^{-1}$ DW based on the conversion factor 5: 1 (wet weight: dry weight). The TMF of BMAA from phytoplankton (average $0.14 \mu \mathrm{g} \mathrm{g}^{-1} \mathrm{DW}$ ) to these animals were about 30.1, 42.5, and 74.4, respectively (Fig. 6). The production ability of diatom-dominated phytoplankton in this study was higher $1^{\sim} 2$ orders of magnitude of that produced by cyanobacteria in Baltic Sea ${ }^{20}$. The concentrations of invertebrates (mussels and oysters, TMF $7^{\sim} 22$ ) and various vertebrates (fish, TMF up to 200 in some tissues of fish) also demonstrated the magnification of BMAA along food chains ${ }^{20}$, but a recent study questioned the concentration of BMAA in the benthic fishes in the ecosystem of Baltic Sea ${ }^{45}$. However, the detection of BMAA with higher concentrations in gastropod mollusks living in the benthic ecosystem was consistent with that of fishes living closer to the bottom of the Baltic Sea which also contained higher BMAA concentrations than pelagic fishes ${ }^{20}$. It is possible that BMAA settles to benthic environments with the death of cyanobacteria and diatoms and subsequently stored in marine sediments. More research is required to discover the accumulation mechanism within marine animals living in the benthic ecosystem. Compared to another study, although the total average concentration of BMAA detected in freshwater cyanobacterial samples $\left(4.12 \mu \mathrm{g} \mathrm{g}^{-1} \mathrm{DW}\right)$ from Gonghu Bay, Taihu Lake, China ${ }^{46}$ is about 30 times that detected in the diatom-dominated phytoplankton from Jiaozhou Bay $\left(0.14 \mu \mathrm{g} \mathrm{g}^{-1} \mathrm{DW}\right)$, the average concentration of BMAA detected in the high-trophic $N$. didyma $\left(21.4 \mu \mathrm{g} \mathrm{g}^{-1} \mathrm{DW}\right)$ in this study is about 5-times higher than that in the freshwater mollusks and crustaceans (3.21 and $\left.3.76 \mu \mathrm{g} \mathrm{g}^{-1} \mathrm{DW}\right)$ reported in the previous study ${ }^{46}$. This phenomenon demonstrated that the TMF of BMAA from producer to benthic animals in the marine ecosystem studied here is great higher than that in the freshwater ecosystem of Gonghu Bay.

Results showed that BAMA was more widely present than BMAA and other isomers in phytoplankton and zooplankton samples collected from Jiaozhou Bay in this study. Unfortunately, the lack of commercialized BAMA reference material restricted an accurate analysis of this compound. Therefore, BAMA was verified by the precolumn AQC-derivatization method using C18 column for most of samples because it does not have baseline separation from BMAA on the HILIC column. In order to assess the variation trend of BAMA in different trophic organisms, the concentration of BAMA was estimated by the mass spectrometry response of BMAA standard in this study. We note that the ratios of BAMA to BMAA in different organisms roughly tended to decrease with increasing trophic levels. The relationship between BAMA and BMAA requires further studies to be explained in detail in the future.

The phytoplankton community ( $>20 \mu \mathrm{m}$ ) was dominated by diatoms in Jiaozhou Bay in all four seasons in 2019 in this study, which was also consistent with some previous studies using $76 \mu \mathrm{m}$-net ${ }^{47-49}$. The density ratio of dinoflagellate to diatom in most months was less than 0.2 , except in July, in $2010^{47}$, and the annual average ratio of dinoflagellate to diatom was less than 0.08 in $2011^{48}$. Diatoms were the most dominant phytoplankton group throughout the year in 2017, except in spring and winter, whenNoctiluca scintillans 
was co-dominant ${ }^{49}$. In this study, only the dinoflagellate Ceratium kofoidii was co-dominant species in June, and diatoms Skeletonema spp.,Chaetoceros spp., Thalassiosira spp. were co-dominant species almost in the whole year. The positive detection of BMAA in phytoplankton net samples suggested that diatoms may be the producer of BMAA in Jiaozhou Bay. The production of BMAA in marine diatoms ${ }^{17-19,50}$ and freshwater diatoms ${ }^{51}$ have been reported in some previous studies. Therefore, a total of 56 strains of diatoms pertaining to five genera including Pseudo-nitzschia, Chaetoceros, Thalassiosira, Planktoniella, and Minidiscus were analyzed for BMAA, in which only Thalassiosira and Chaetoceros were reported before to produce BMAA. In the previous study by Jiang et al ${ }^{17}$, five genera of diatoms (Achnanthes sp., Navicula pelliculosa, Proboscia inermis, Skeletonema marinoi, Thalassiosira sp.) were cultured and tested to produce BMAA, in which the concentration of protein-bound BMAA in T. sp. was $3.28 \mathrm{ng} \mathrm{g}^{-1} \mathrm{DW}$. Seven species of marine diatoms (Navicula pelliculosa, Chaetoceros socialis ,Coscinodiscus granii, Thalassiosira weissflogii ,Phaeodactylum tricornutum, Skeletonema marinoi ,Ditylum brightwellii ) were cultured and analyzed for BMAA, in which the concentration of protein-bound BMAA in Ch. socialis and T. weissflogii were 0.62 and $2.19 \mu \mathrm{g} \mathrm{g}^{-1}$ DW, respectively, and varied concentration of free-form BMAA was also detected except for $D$. brightwellii 50. The highest production of BMAA was observed at the stationary growth phase of four diatom strains includingPh. tricornutum, Ch. sp., Ch. calcitrans, and T. pseudonana, at 1.4, 1.6, 1.8, and $0.28 \mu \mathrm{g}$ $\mathrm{g}^{-1}$ DW, respectively ${ }^{18}$. Large discrepancy of BMAA concentration occurred in the laboratory cultures of Thalasososira and Chaetoceros in above different studies. In this study, 37.5\% (21/56) of the studied diatom strains contained the protein-bound BMAA which belonged to four genera except for Minidiscus . Only three species of Minidiscus were cultured and analyzed here (Supplementary Table 5), and we could not determine that the diatoms of this genus are non-toxic for BMAA due to variation of BMAA production in the same diatom genus. Interestingly, BMAA was mainly present in the precipitated-bound fraction of the diatom cultures, followed by the total soluble fraction. In the genusPseudo-nitzschia, a total of 9 strains detected BMAA, in whichPs. multiseries $\left(0.41 \mu \mathrm{g} \mathrm{g}{ }^{-1} \mathrm{DW}\right)$ and Ps. caciantha $\left(0.30 \mu \mathrm{g} \mathrm{g}^{-1} \mathrm{DW}\right)$ cultures contained total soluble BMAA, and the other 7 strains were only found precipitated bound BMAA ranging with $0.11^{\sim} 3.05 \mu \mathrm{g} \mathrm{g}^{-1}$ DW. In the genus Thalassiosira , 8 strains detected BMAA in the precipitated bound fraction ranging from $0.33^{\sim} 3.95 \mu \mathrm{g} \mathrm{g}^{-1} \mathrm{DW}$, in which T. minima, T. alleniiand T. gravida also contained total soluble BMAA. In the genusChaetoceros , 3 strains contained precipitated bound BMAA below $0.3 \mu \mathrm{g}$ $\mathrm{g}^{-1} \mathrm{DW}$. The precipitated bound BMAA was also detected in a strain of Planktoniella at $0.16 \mu \mathrm{g} \mathrm{g}^{-1} \mathrm{DW}$. The average production level of BMAA in different diatom genera decreased in order of Thalasosira $(2.07 \mu \mathrm{g}$ $\left.\mathrm{g}^{-1} \mathrm{DW}\right)>$ Pseudo-nitzschia $\left(1.00 \mu \mathrm{g} \mathrm{g} \mathrm{g}^{-1} \mathrm{DW}\right)>$ Planktoniella $\left(0.16 \mu \mathrm{g} \mathrm{g}^{-1} \mathrm{DW}\right)>$ Chaetoceros $\left(0.12 \mu \mathrm{g} \mathrm{g}{ }^{-1}\right.$ DW). Among the positively detected strains of diatoms, 40-fold difference of BMAA concentration between the highest (T. minima , $3.95 \mu \mathrm{g} \mathrm{g}^{-1} \mathrm{DW}$ ) and the lowest (Ps. sp., $0.11 \mu \mathrm{g} \mathrm{g}^{-1} \mathrm{DW}$ ) level. An additional batch culture of some BMAA-producing strains of diatoms was conducted to confirm the BMAA-producing ability of diatoms was steady and specific. The results showed that diverse diatom strains isolated from Chinese coast could produce BMAA dominated in the precipitated bound fraction. The distribution form of BMAA in the cultures of isolated diatom strains was largely different from that in the phytoplankton collected from Jiaozhou Bay. Additionally, the isomer BAMA was not found in the laboratory cultures although it was ubiquitous in the field diatom-dominated phytoplankton samples. This discrepancy hints that the production of BMAA in diatoms is affected by environmental factors such as nutrient, temperature, predator pressure, etc. What is the real source of BAMA in the phytoplankton samples collected from Jiaozhou Bay? How do the environmental factors regulate the production of BMAA by diatoms? These problems should be deeply explored in further studies.

Misincorporation of BMAA into proteins in the place of $L$-serine has been considered as a bioaccumulation and pathogenic mechanism for neurodegenerative diseases ${ }^{33,34,52}$, but some studies also demonstrated that BMAA was not be miscoded into proteins in higher organisms ${ }^{53,54}$ which was reviewed and proposed as a result of differing methodologies ${ }^{55}$. In this study, BMAA in diatoms was the highest in the proteinbound form. So far the biosynthesis of BMAA is still unknown. However, the analytical results of BMAA in the cultures of diatom strains demonstrated that the production of BMAA in diatoms was species- or strain-specific, and affected by nutrient conditions ${ }^{19}$. For example, the production of BMAA varied in the strains MC4451, MC4185, and MC4423 ofPs. multiseries isolated from Taiwan Strait Y13, Taiwan 
Strait E6, and Taiwan Strait Y23, respectively. The strain MC4451 produced total soluble BMAA, while MC4185 produced precipitated bound BMAA and MC4423 did not produce BMAA. The strains MC6394 and MC6056 of Planktoniella blanda were isolated from Taiwan Strait Y11 and Hong Kong, respectively, in which the former produced precipitated bound BMAA but the latter did not. The strains MC6475 (from Shantou Nan'ao Treasure Island) and MC6447 (Tsing Yi, Hong Kong) of Thalassiosira minima have the same pattern. As it has been pointed above that the BMAA form in the field phytoplankton collected from Jiaozhou Bay was different from that in the cultures of isolated diatom strains under laboratory conditions. We hypothesize that environmental stress or ecological predatory pressure from zooplankton induce diatoms to release a free form BMAA from the protein-bound fraction through the nitrogenous metabolism pathways.

In the present study, the benthic and carnivorous gastropod $N$. didyma was identified again as a typical vector for BMAA in Jiaozhou Bay ecosystem, of which the average concentration of BMAA reached $21.4 \mu \mathrm{g}$ $\mathrm{g}^{-1} \mathrm{DW}$ corresponding to the TMF of about 150 from phytoplankton. In order to explore the production ability of BMAA by the symbiotic bacteria in the gut of $N$. didyma, a total of 7 species of symbiotic bacteria were cultured and identified for toxin analysis. Results showed that none of these bacteria produced BMAA, but DAB was detected in all samples, which supports the hypothesis that the neurotoxin BMAA detected in $N$. didyma was accumulated from food chains. In addition, DAB, as an isomer of BMAA, has been detected before in diverse organisms such as cyanobacteria, phytoplankton, zooplankton, mollusks, etc. ${ }^{19,24,25,30,38,40}$, but we hypothesize that the marine bacteria isolated from the gastropod gut are possible source of DAB detected in aquatic organisms. Interestingly, some unknown compounds were also detected in these bacteria with the same transition ions as $\mathrm{DAB}$, which may be precursor compounds relative to DAB. If true, DAB could also be produced by some heterotrophic prokaryotes in the environment, but no significant biomagnification phenomenon has been reported for DAB in aquatic ecosystems including this study. However, BMAA is known to be produced only by autotrophic prokaryotes (cyanobacteria) or eukaryotes (diatom or dinoflagellate) in aquatic environments. More research is needed to determine the biosynthesis of BMAA, BAMA and DAB in marine environments.

\section{Materials and Methods}

Chemicals. The reference materials $L$-BMAA hydrochloride (B107, $10 \mathrm{mg}$ ) and $D L$-2,4-diaminobutyric acid dihydrochloride (DAB, D3758, $1 \mathrm{~g}$ ) were purchased from Sigma-Aldrich (Oakville, ON, Canada), and $N$-2(aminoethyl) glycine (AEG, A608975, $1 \mathrm{~g}$ ) standard was purchased from Toronto Research Chemicals Inc. (Canada). The reagents methanol, acetonitrile and formic acid (FA) were HPLC grade (Merck, Germany). Ammonium formate $\left(\mathrm{NH}_{4} \mathrm{COOH}\right)$ and trichloroacetic acid (TCA) were purchased from SigmaAldrich. AccQ-Fluor Reagent Kit was purchased from Waters (Taunton, MA, USA). The pure water was obtained by a MilliQ water purification system (Millipore Ltd., SAS. Mosheim, France) to $18.2 \mathrm{M} \Omega \mathrm{cm}$ resistivity or better.

Field sample collection. Samples of diatom and zooplankton were collected using HydroBios net from bottom to surface at 12 sampling positions (Fig. 1) in Jiaozhou Bay in January, March, June, and September 2019. Zooplankton samples were retained by a shallow water type I plankton net $(505-\mu \mathrm{m}$ mesh, $50-\mathrm{cm}$ diameter, and net length $145 \mathrm{~cm}$ ), and phytoplankton samples were concentrated by a shallow water type III plankton net $(20-\mu \mathrm{m}$ mesh, 37 -cm diameter, and net length $140 \mathrm{~cm})$ and filtered by a $200-\mu \mathrm{m}$ sieve to remove larger particles. A portion of plankton sub-samples from each station were spiked with a final concentration of $5 \%$ formaldehyde solution and stored for species identification. A phytoplankton sample $(0.25 \mathrm{~mL})$ was transferred to a Palmer-Maloney counting box and observed using light microscopy (BX53, Olympus) for species identification and cell density counting. The Leica S8APO stereo microscope was used to observe and count zooplankton species, and all species presenting in the samples were identified and counted. During the counting process, according to the density of zooplankton in the original sample, a Folsom's Plankton Sample Divider was used (generally, zooplankton is divided into specific levels in 1/4,1/16,1/64, and 1/256), to ensure that the number of zooplanktons in each sample was above 200. Meanwhile, aquatic animals of mollusks and crustacea were purchased from fishermen or local seafood markets, all of which are important seafood products for daily consumption by residents. 
Culture of isolated diatom strains. A total of 56 strains of diatoms isolated from Chinese coasts and provided by the diatom collection of South China Normal University were cultured in our laboratory using $\mathrm{f} / 2$ medium. All cultures were kept at 20 with a cycle of 12-h light: 12-h dark, at a light intensity of $6000 \mathrm{~lx}$, which were usually lightly shaken three times daily. In the first batch culture, all 56 strains were cultured and scanned for BMAA. In the second batch culture, 11 of 21 strains containing BMAA were cultured in triplicate and collected at the stationary growth phase for the second analysis of BMAA and its isomers.

Culture and identification of symbiotic bacteria. The guts of healthy gastropods Neverita didyma $(\mathrm{n}>10)$ were dissected and homogenized by a tissue homogenizer. The gut debris was diluted using different gradients of normal saline. The spread plate method was used to isolate and culture microorganisms. Part of $100 \mu \mathrm{L}$ of gut solution were evenly spread on the surface of beef extract peptone medium and $2216 \mathrm{E}$ medium, respectively, and subsequently transferred to a biochemical incubator at 26 in order to culture bacterial colonies. Finally, the bacterial colonies were purified using a suitable gradient medium. Monoclonal colonies with different characteristics were picked by streak plate method. A total of 9 strains were isolated and cultured for toxin analysis. The isolated strains were stored in a refrigerator at 4 for other experiments. Molecular 16S rDNA analysis was adopted to identify the DAB-producing bacteria. The $16 \mathrm{~S}$ rDNA was amplified by PCR with general primers (27F and 1492R), which were sent directly to BGI (Beijing Genomics Institute) for sequencing. For identification of bacteria, DNA sequences were analyzed by the Basic Local Alignment Search Tool at the NCBI (National Center for Biotechnology Information) website. Finally, two bacterial strains were identified as the same species, and one strain was not successfully sequenced.

Pretreatment for biological samples. Field plankton samples were filtered by a $2.7 \mu \mathrm{m}$ glass fiber membrane. Mollusks and crustacea samples were dissected by a scalpel and all soft tissues were homogenized for toxin extraction. All laboratory cultures of diatom strains were collected by centrifugation at $6577 \times \mathrm{g}$ when they entered the stationary growth phase before toxin extraction. All above samples were stored at -20 immediately after processing.

Extraction for the total soluble form of BMAA . The membranes containing plankton samples were removed from the refrigerator and allowed to reach room temperature. The samples were then placed in an oven at 55 until their weight did not change and the dry weight of samples was calculated through subtracting the average weight of blank membranes. Subsequently, the membranes were completely shredded and transferred into a $10 \mathrm{~mL}$ centrifuge tube. Five $\mathrm{mL}$ of $0.1 \mathrm{~mol} \mathrm{~L}^{-1}$ trichloroacetic acid (TCA) were added to the tube. The mixture was then frozen in liquid nitrogen for $10 \mathrm{~min}$ and thawed at room temperature, which was repeated three times. The thawed samples were ultrasonically broken for $20 \mathrm{~min}$ with an icewater bath. Finally, $2 \mathrm{~mL}$ of the supernatant was removed by centrifugation and dried under $\mathrm{N}_{2}$ gas at 55 $\operatorname{deg} \mathrm{C}$. The residual materials were re-dissolved in $6 \mathrm{~mol} \mathrm{~L}^{-1} \mathrm{HCl}$ and hydrolyzed at $110 \operatorname{degC}$ for $24 \mathrm{~h}$ to get the soluble-bound form of BMAA. The hydrolyzed solution was dried again and reconstituted with 20 mmol L ${ }^{-1} \mathrm{HCl}$. Prior to analysis for BMAA using HILIC-MS/MS, the extract was purified using solid-phase extraction $(\mathrm{SPE})^{56}$ with minor modifications. The Oasis-MCX SPE cartridges $(3 \mathrm{cc}, 60 \mathrm{mg})$ were activated by $3 \mathrm{~mL}$ of methanol and $3 \mathrm{~mL}$ of $5 \% \mathrm{NH}_{4} \mathrm{OH}$ were used to elute toxins.

Cultures of the isolated diatom strains were lyophilized in a vacuum freeze dryer for $24 \mathrm{~h}$ and then transferred to a $10 \mathrm{~mL}$ centrifuge tube. The toxin extraction steps followed the same procedure as that used for the field plankton samples described above.

Mollusk or crustacea tissues $(0.5 \mathrm{~g})$ were mixed with $3 \mathrm{~mL}$ of $0.1 \mathrm{~mol} \mathrm{~L}^{-1} \mathrm{TCA}$ and homogenized by a tissue homogenizer. Supernatant was transferred to a $10 \mathrm{~mL}$ volumetric flask after centrifugation at $6577 \mathrm{x} g$ for $10 \mathrm{~min}$. The above extraction steps were repeated three times. The combined supernatant was finally made up to $10 \mathrm{~mL}$. An aliquot of the supernatant $(1 \mathrm{~mL})$ was dried under $\mathrm{N}_{2}$ gas at $55 \operatorname{deg} \mathrm{C}$ and the residual material was re-dissolved in $6 \mathrm{~mol} \mathrm{~L} \mathrm{~L}^{-1} \mathrm{HCl}$ and hydrolyzed at $110 \operatorname{deg} \mathrm{C}$ for $24 \mathrm{~h}$. The hydrolysis solution was dried again and reconstituted in $20 \mathrm{mmol} \mathrm{L}^{-1} \mathrm{HCl}$ before purification using the above SPE treatment.

Extraction for the precipitated bound BMAA . The precipitated bound BMAA was also analyzed in 
the cultures of isolated diatom strains. In the process for extracting soluble BMAA, the microalgal deposit was mixed with $3 \mathrm{~mL}$ of $6 \mathrm{~mol} \mathrm{~L}^{-1} \mathrm{HCl}$, vortexed and transferred to a $4 \mathrm{~mL}$ glass bottle. The mixture was hydrolyzed at $110 \mathrm{degC}$ for $24 \mathrm{~h}$ and then transferred to a $10 \mathrm{~mL}$ centrifuge tube. The glass vial was rinsed with $1 \mathrm{~mL}$ of $6 \mathrm{~mol} \mathrm{~L}^{-1} \mathrm{HCl}$ and then combined into the $10 \mathrm{~mL}$ centrifuge tube follow by centrifugation at $6577 \mathrm{xg}$ for $10 \mathrm{~min}$. Two $\mathrm{mL}$ of supernatant were dried under $\mathrm{N}_{2}$ gas at $55 \operatorname{deg} \mathrm{C}$ and the residue was reconstructed in $1 \mathrm{~mL}$ of $20 \mathrm{mmol} \mathrm{L}^{-1} \mathrm{HCl}$ before purification using SPE treatment described above.

HILIC-MS/MS analysis. Analysis for BMAA and its isomers was conducted on a Thermo Ultimate 3000 HPLC (Thermo Fisher Scientific, Bremen, Germany) coupled with an AB-Sciex Qtrap 4500 mass spectrometer (AB Sciex Pte. Ltd, Singapore) with an electrospray ionization source. A binary mobile phase system composed of water (solvent A) and acetonitrile (solvent B) each with $0.1 \%$ formic acid was used to separate chemical targets on a SeQuant ${ }^{(\mathrm{r})}$ ZIC-HILIC $^{(\mathrm{r})}$ column $(150 \mathrm{~mm} \times 2.1 \mathrm{~mm}, 5 \mu \mathrm{m})$ maintained at 30 . The gradient was linear from $95 \%$ to $60 \%$ solvent B over 19 min and then decreased to $40 \%$ B at 25 min, and increased to $95 \% \mathrm{~B}$ at $27.01 \mathrm{~min}$, held for $2.99 \mathrm{~min}$ before re-equilibration. The flow rate was set at $350 \mu \mathrm{L} \mathrm{min}{ }^{-1}$ and injection volume was set at $5 \mu \mathrm{L}$. The electro-spray voltage was set to $5500 \mathrm{~V}$ with a source temperature of 350 . Nitrogen was used for the nebulizer and curtain gases. The selective reaction monitoring (SRM) mode was used to quantify BMAA and its isomers. Five transitions $m / z 119->102,101$, 88,56 , and 44 (CE: 13, 11, 17, 24, and $24 \mathrm{eV}$ ) were used for BMAA and its isomers. BMAA and DAB was quantified by the $m / z 119->88$ and $119->101$, respectively, and $119->102$ was used to semi-quantify BAMA.

Statistical analysis. Trophic magnification factor (TMF) was calculated by the ratio of BMAA concentrations in organisms within different trophic levels to the average concentration of BMAA in phytoplankton samples. The average concentration of BMAA in phytoplankton as well as zooplankton was taken from the average value of the total concentration of BMAA in biological samples from 12 sampling stations. The average concentrations of BMAA in bivalve and gastropod mollusks and crustacea animals were taken from the average concentrations of BMAA in different species of animals within each trophic level. Data processing was performed using the Microsoft Excel 2016 software (Microsoft Corporation, Redmond, USA). Figures of data and sampling station map were performed using the Origin 2018 (OriginLab Corporation, Northampton, USA) and ArcGIS Desktop 10.2 software (ESRI Corporation, Redlands, CA), respectively.

\section{References}

1. Banack, S. A., Caller, T. A. \& Stommel, E. W. The cyanobacteria derived toxin beta-N-methylaminoL-alanine and amyotrophic lateral sclerosis. Toxins . 2 , 2837-2850 (2010).

2. Lobner, D., Piana, P. M. T., Salous, A. K. \& Peoples, R. W. $\beta-N$-methylamino-L-alanine enhances neurotoxicity through multiple mechanisms. Neurobiol. Dis . 25, 360-366 (2007).

3. Rao, S. D., Banack, S. A., Cox, P. A. \& Weiss, J. H. BMAA selectively injures motor neurons via AMPA/kainate receptor activation.Exp . Neurol . 201 , 244-252 (2006).

4. Murch, S. J., Cox, P. A., Banack, S. A., Steele, J. C. \& Sacks, O. W. Occurrence of beta-methylaminol-alanine (BMAA) in ALS/PDC patients from Guam. Acta . Neurol . Scand . 110, 267-269 (2004).

5. Cox, P. A., Banack, S. A. \& Murch, S. J. Biomagnification of cyanobacterial neurotoxins and neurodegenerative disease among the Chamorro people of Guam. Proc . Natl . Acad .Sci . USA 100 , 13380-13383 (2003).

6. Brand, L. E., Pablo, J., Compton, A., Hammerschlag, N. \& Mash, D. C. Cyanobacterial blooms and the occurrence of the neurotoxin, beta-N-methylamino-L-alanine (BMAA), in South Florida aquatic food webs. Harmful Algae . 9, 620-635 (2010).

7. Cox, P. A. et al. Diverse taxa of cyanobacteria produce $\beta-N$-methylamino-l-alanine, a neurotoxic amino acid.Proc . Natl . Acad . Sci . USA102, 5074-5078 (2005).

8. Banack, S. A., Johnson, H. E., Cheng, R. \& Cox, P. A. Production of the neurotoxin BMAA by a marine cyanobacterium. Mar.Drugs . 5 , 180-196 (2007).

9. Esterhuizen, M. \& Downing, T. G. $\beta-N$-methylamino-L-alanine (BMAA) in novel South African 
cyanobacterial isolates. Ecotoxicol . Environ .Saf . 71, 309-313 (2008).

10. Metcalf, J. S. et al. Co-occurrence of $\beta$-N-methylamino-L-alanine, a neurotoxic amino acid with other cyanobacterial toxins in British waterbodies, 1990-2004. Environ. Microbiol . 10 , 702-708 (2008).

11. Johnson, H. E. et al. Cyanobacteria (Nostoc commune) used as a dietary item in the Peruvian highlands produce the neurotoxic amino acid BMAA. J . Ethnopharmacol . 118, 159-165 (2008).

12. Downing, S., Banack, S. A., Metcalf, J. S., Cox, P. A. \& Downing, T. G. Nitrogen starvation of cyanobacteria results in the production of $\beta-N$-methylamino-L-alanine. Toxicon . 58 , 187-194 (2011).

13. Monteiro, M., Costa, M., Moreira, C., Vasconcelos, V. M. \& Baptista, M. S. Screening of BMAAproducing cyanobacteria in cultured isolates and in in situ blooms. J . Appl . Phycol .29, 879-888 (2017).

14. Main, B. J. et al. Detection of the suspected neurotoxin $\beta$-methylamino-L-alanine (BMAA) in cyanobacterial blooms from multiple water bodies in Eastern Australia. Harmful Algae 74, 10-18 (2018).

15. Jiang, L. \& Ilag L. L. Detection of endogenous BMAA in dinoflagellate (Heterocapsa triquetra) hints at evolutionary conservation and environmental concern. PubRaw Sci . 1 , 1-8 (2014).

16. Lage, S. et al. BMAA in shellfish from two Portuguese transitional water bodiessuggests the marine dinoflagellate Gymnodinium catenatum as apotential BMAA source. Aquat . Toxicol .152, 131-138 (2014).

17. Jiang, L. et al. Diatoms: a novel source for the neurotoxin BMAA in aquatic environments. PloS One . 9, e84578 (2014).

18. Réveillon, D., Séchet, V., Hess, P. \& Amzil, Z. Production of BMAA and DAB by diatoms (Phaeodactylum tricornutum, Chaetoceros sp., Chaetoceros calcitrans and, Thalassiosira pseudonana) and bacteria isolated from a diatom culture. Harmful Algae. 58 , 45-50 (2016).

19. Lage, S., Ström, L., Godhe, A. \& Rydberg, S. Kinetics of $\beta$-N-methylamino-L-alanine (BMAA) and 2, 4-diaminobutyric acid (DAB) production by diatoms: the effect of nitrogen. Eur . J .Phycol . 54, 115-125 (2019).

20. Jonasson, S. et al. Transfer of a cyanobacterial neurotoxin within a temperate aquatic ecosystem suggests pathways for human exposure.Proc . Natl . Acad . Sci . USA107, 9252-9257 (2010).

21. $\mathrm{Wu}, \mathrm{X}$. et al. Biomagnification characteristics and health risk assessment of the neurotoxin BMAA in freshwater aquaculture products of Taihu Lake Basin, China. Chemosphere . 229 , 332-340 (2019).

22. Lage, S., Annadotter, H., Rasmussen, U. \& Rydberg, S. Biotransfer of $\beta$ - $N$-methylamino-L-alanine (BMAA) in a eutrophicated freshwater lake. Mar . Drugs . 13, 1185-1201 (2015).

23. Banack, S. A. et al. Detection of cyanotoxins, $\beta-N$-methylamino-L-alanine and microcystins, from a lake surrounded by cases of Amyotrophic Lateral Sclerosis. Toxins .7 , 322-336 (2015).

24. Réveillon, D. et al. $\beta-N$-methylamino-L-alanine (BMAA) and isomers: Distribution in different food web compartments of Thau lagoon, French Mediterranean Sea. Mar . Environ .Res . 110, 8-18 (2015).

25. Réveillon, D., Séchet, V., Hess, P. \& Amzil, Z. Systematic detection of BMAA ( $\beta$-N-methylamino-Lalanine) and $\mathrm{DAB}$ (2,4-diaminobutyric acid) in mollusks collected in shellfish production areas along the French coasts. Toxicon . 110, 35-46 (2016).

26. Masseret, E. et al. Dietary BMAA exposure in an Amyotrophic Lateral Sclerosis cluster from southern France. PloS One . 8, e83406 (2013).

27. Salomonsson, M. L., Fredriksson, E., Alfjorden, A., Hedeland, M. \& Bondesson, U. Seafood sold in Sweden contains BMAA: A study of free and totalconcentrations with UHPLC-MS/MS and dansyl chloridederivatization. Toxicol . Rep . 2, 1473-1481 (2015).

28. Jiang, L., Kiselova, N., Rosén, J. \& Ilag, L. L. Quantification of neurotoxin BMAA ( $\beta-N$-methylaminoL-alanine) in seafood from Swedish markets. Sci . Rep . 4, 6931 (2014).

29. Li, A. et al. New typical vector of neurotoxin $\beta-N$-methylamino-L-alanine (BMAA) in the marine benthic ecosystem. Mar. Drugs . 14, 202 (2016).

30. Li, A., Hu, Y., Song, J., Wang, S. \& Deng, L. Ubiquity of the neurotoxin $\beta-N$-methylamino- $L$-alanine and its isomers confirmed by two different mass spectrometric methods in diverse marine mollusks. 
Toxicon . 151, 129-136 (2018).

31. Mondo, K. et al. Cyanobacterial neurotoxin $\beta-N$-methylamino-L-alanine (BMAA) in shark fins. Mar Drugs . 10 , 509-520 (2012).

32. Pablo, J. et al. Cyanobacterial neurotoxin BMAA in ALS and Alzheimer's disease. Acta . Neurol . Scand . 120 , 216-225 (2009).

33. Dunlop, R. A., Cox, P. A., Banack, S. A. \& Rodgers, K. J. The non-protein amino acid BMAA is misincorporated into human proteins in place of L-Serine causing protein misfolding and aggregation.PloS One . 8, e75376 (2013).

34. Murch, S. J., Cox, P. A. \& Banack, S. A. A mechanism for slow release of biomagnified cyanobacterial neurotoxins and neurodegenerative disease in Guam. Proc . Natl . Acad . Sci.USA 101, 12228-12231 (2004).

35. Cox, P. A., Davis, D. A., Mash, D. C., Metcalf, J. S. \& Banack, S. A. Dietary exposure to an environmental toxin triggers neurofibrillary tangles and amyloid deposits in the brain. Proc . R .Soc . B 283 , 20152397 (2016).

36. Korn, A. et al. Incorporation of the Nonproteinogenic Amino Acid $\beta$-Methylamino-alanine Affects Amyloid $\beta$ Fibril Properties and Toxicity. ACS Chem . Neurosci . 11, 1038-1047 (2020).

37. Bishop, S. L. \& Murch, S. J. A systematic review of analytical methods for the detection and quantification of $\beta-N$-methylamino-L-alanine (BMAA). Analyst . 145 , 13-28 (2020).

38. Fan, H., Qiu, J., Fan, L. \& Li, A. Effects of growth conditions on the production of neurotoxin 2,4diaminobutyric acid (DAB) inMicrocystis aeruginosa and its universal presence in diverse cyanobacteria isolated from freshwater in China. Environ .Sci . Pollut . Res . 22, 5943-5951 (2015).

39. Rosén, J. \& Hellenäs, K.-E. Determination of the neurotoxin BMAA ( $\beta$ - $N$-methylamino-L-alanine) in cycad seed and cyanobacteria by LC-MS/MS (liquid chromatography tandem mass spectrometry).Analyst . $133,1785-1789$ (2008).

40. Krüger, T., Mönch, B., Oppenhäuser, S. \& Luckas, B. LC-MS/MS determination of the isomeric neurotoxins BMAA ( $\beta$ - $N$-methylamino-L-alanine) and DAB (2,4-diaminobutyric acid) in cyanobacteria and seeds of Cycas revoluta and Lathyrus latifolius. Toxicon . 55 , 547-557 (2010).

41. Faassen, E. J., Gillissen, F. \& Lürling M. A comparative study on three analytical methods for the determination of the neurotoxin BMAA in cyanobacteria. PloS One . 7 , e36667 (2012).

42. Tymm, F. J. M., Bishop, S. L. \& Murch, S. J. A single laboratory validation for the analysis of underivatized $\beta$-N-methylamino-L-alanine (BMAA). Neurotox . Res . 1-23 (2019).

43. Lance, E., Arnich, N., Maignien, T. \& Biré, R. Occurrence of $\beta-N$-methylamino-l-alanine (BMAA) and Isomers in Aquatic Environments and Aquatic Food Sources for Humans. Toxins .10 , 83 (2018).

44. Chernoff, N. et al. A critical review of the postulated role of the non-essential amino acid, $\beta$-Nmethylamino-L-alanine, in neurodegenerative disease in humans. J . Toxicol .Environ. Health B Crit. Rev . 20 , 183-229 (2017).

45. Zguna, N., Karlson, A. M. L., Ilag, L. L., Garbaras, A. \& Gorokhova, E. Insufficient evidence for BMAA transfer in the pelagic and benthic food webs in the Baltic Sea. Sci . Rep . 9 , 1-11 (2019).

46. Jiao, Y. et al. Occurrence and transfer of a cyanobacterial neurotoxin $\beta$-methylamino-L-alanine within the aquatic food webs of Gonghu Bay (Lake Taihu, China) to evaluate the potential human health risk.Sci . Total Environ. 468, 457-463 (2014).

47. Zheng, S., Sun, X.-X., Zhao, Y.-F. \& Song, S. Annual variation of species composition and abundance distribution of phytoplankton in 2010 in the Jiaozhou Bay. Mar Sci . 38 , 1-6 (2014) (In Chinese).

48. Luo, X., Sun, X.-X., Zheng, S. \& Zhao, Y.-F. On phytoplankton community structure and causative factors in the Jiaozhou Bay in 2011. Oceanologia Et Limnologia Sinica . 47 , 915-923 (2016) (In Chinese).

49. Guo, S. et al. Spatial-temporal variation of phytoplankton community structure in Jiaozhou Bay, China. J . Oceanol Limnol .37, 1611-1624 (2019).

50. Lage, S. et al. BMAA extraction of cyanobacteria samples: which method to choose? Environ . Sci . Pollut. Res .23, 338-350 (2016).

51. Violi, J. P., Facey, J. A., Mitrovic, S. M., Colville, A. \& Rodgers, K. J. Production of $\beta$-methylamino- 
L-alanine (BMAA) and its isomers by freshwater diatoms. Toxins . 11, 512 (2019).

52. Glover, W. B., Mash, D. C. \& Murch, S. J. The natural non-protein amino acid $N$ - $\beta$-methylamino-lalanine (BMAA) is incorporated into protein during synthesis. Amino Acids . 46 , 2553-2559 (2014).

53. van Onselen, R., Venables, L., van de Venter, M. \& Downing, T. G. $\beta$-N-methylamino-L-alanine toxicity in PC12: excitotoxicity vs. misincorporation. Neurotox. Res . 33 , 15-23 (2018).

54. van Onselen, R., Downing, S., Kemp, G. \& Downing, T. Investigating $\beta-N$-methylamino-L-alanine misincorporation in human cell cultures: A comparative study with known amino acid analogues. Toxins . 9, $400(2017)$.

55. Dunlop, R. A. \& Guillemin, G. J. The cyanotoxin and non-protein amino acid $\beta$-methylamino-L-alanine (L-BMAA) in the food chain: Incorporation into proteins and its impact on human health. Neurotox .Res . 36 , 602-611 (2019).

56. Li, A. et al. Elucidation of matrix effects and performance of solid-phase extraction for LC-MS/MS analysis of $\beta-N$-methylamino-L-alanine (BMAA) and 2,4-diaminobutyric acid (DAB) neurotoxins in cyanobacteria. Analyst. 137, 1210-1219 (2012).

\section{Acknowledgments}

This study was supported by the National Natural Science Foundation of China (Grant \# 41676093), and Fundamental Research Funds for Central Universities (Grant \# 201841003). We would like to appreciate Dr. Paul Alan Cox working at Brain Chemistry Labs, Institute for Ethnomedicine, USA, for reviewing this manuscript before submission.

\section{Author Contributions}

C.W. sample collection, data acquisition, statistical analysis, and manuscript preparation; C.Y. sample collection and data acquisition; J.B.Q. sample collection; C.L. sample collection; Y.J.Y. sample collection; Y.J. sample collection; G.X.W. sample collection; H.J.C. identification for zooplankton; Y.L. isolation and identification for diatom strains; S.A.B. manuscript review and editing; A.F.L. guarantor of integrity of entire study, study concepts, study design, manuscript editing.

\section{Competing interests}

The authors declare no competing interests.

\section{Additional information}

Supplementary figures and tables are available for this paper at xxx.

Correspondence and requests for materials should be addressed to A.F.L.

\section{Figures}




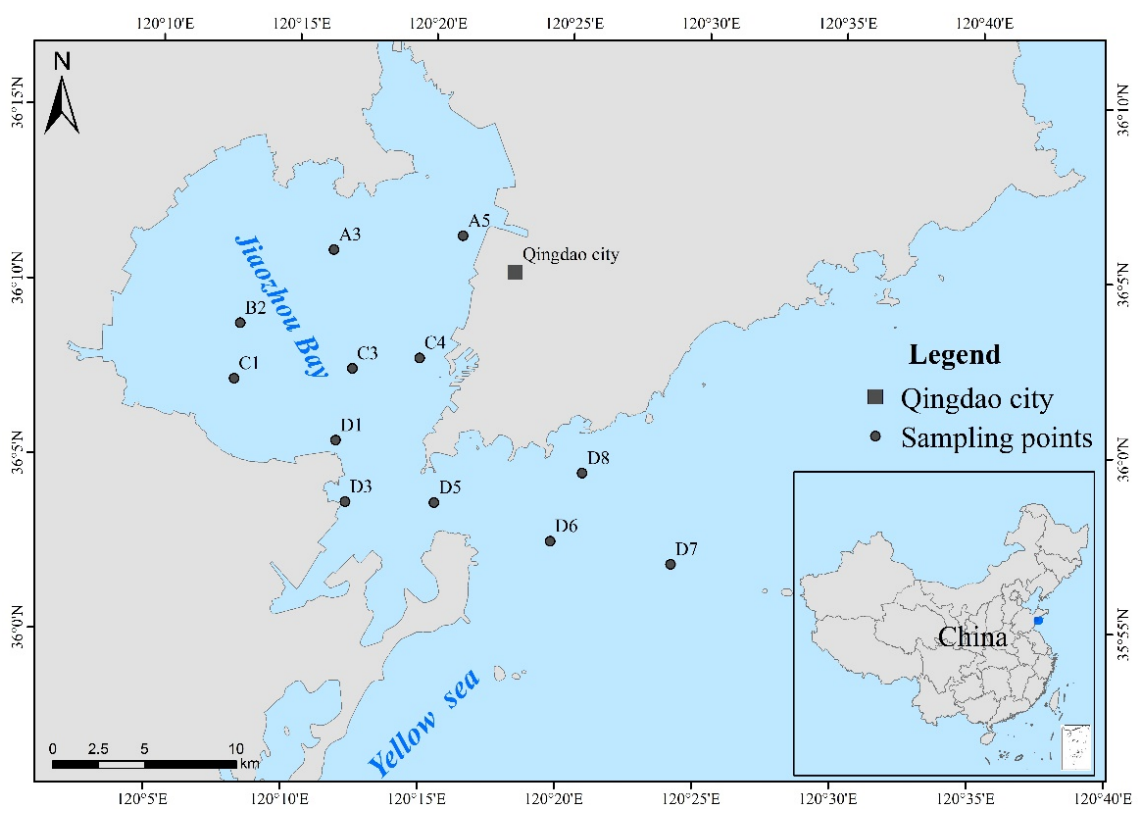

Fig. 1 Sampling stations in Jiaozhou Bay, Yellow Sea of China.A3, A5, B2, C1, C3, C4, D1, D3, D5, D6, D7, D8 were smapling stations for investigation of phytoplankton and zooplankton samples in January, March, June, and September, 2019, respectively. 

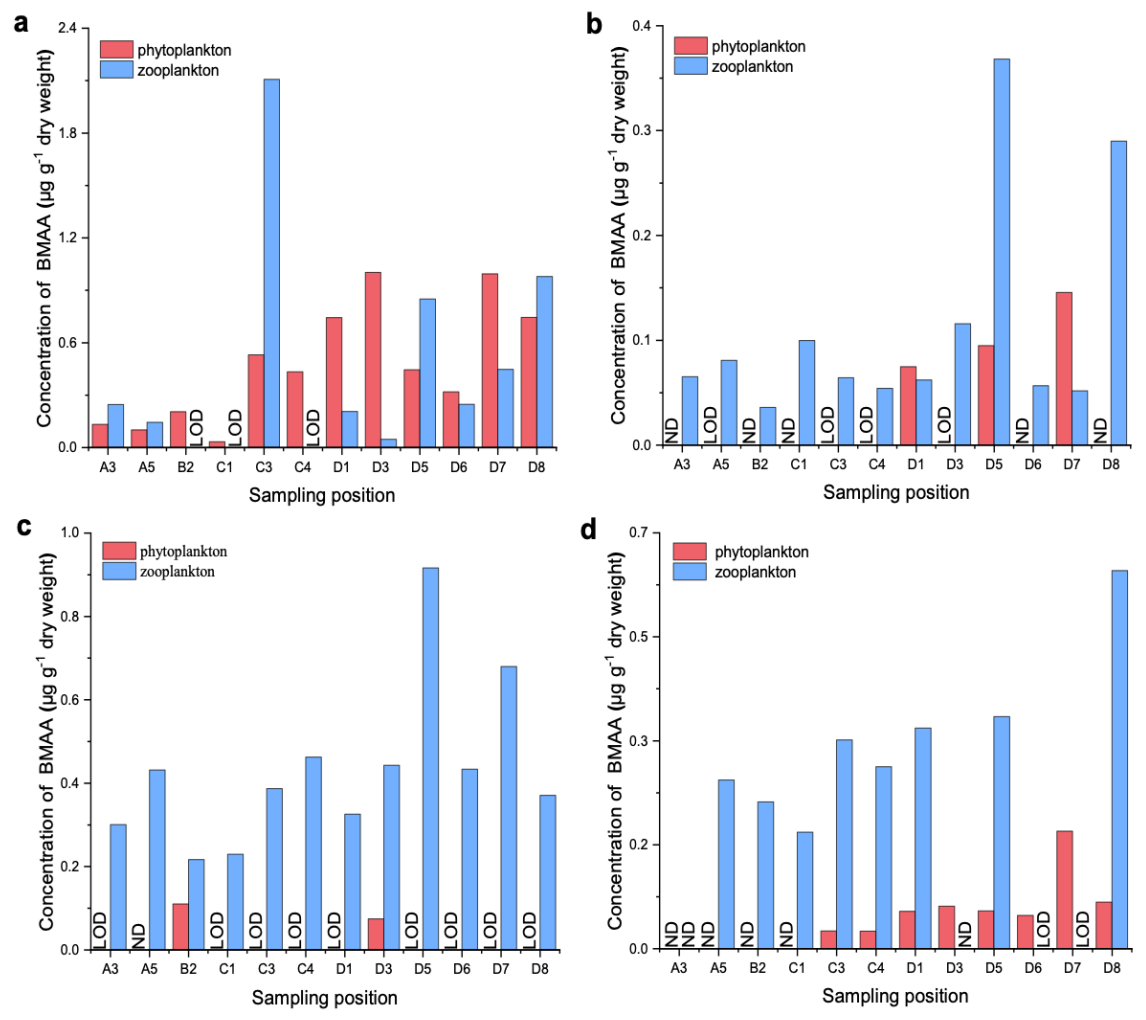

Figure 1: This is a caption

Fig. 2 Concentrations of BMAA in phytoplankton and zooplankton. The unit of BMAA concentration is $\mu \mathrm{g} \mathrm{g}^{-1}$ dry weight of biological samples collected from Jiaozhou Bay in (a) January, (b) March, (c) June, and (d) September, respectively. LOD means the concentration was lower than limit of detection, and ND means no BMAA was detected in samples. 


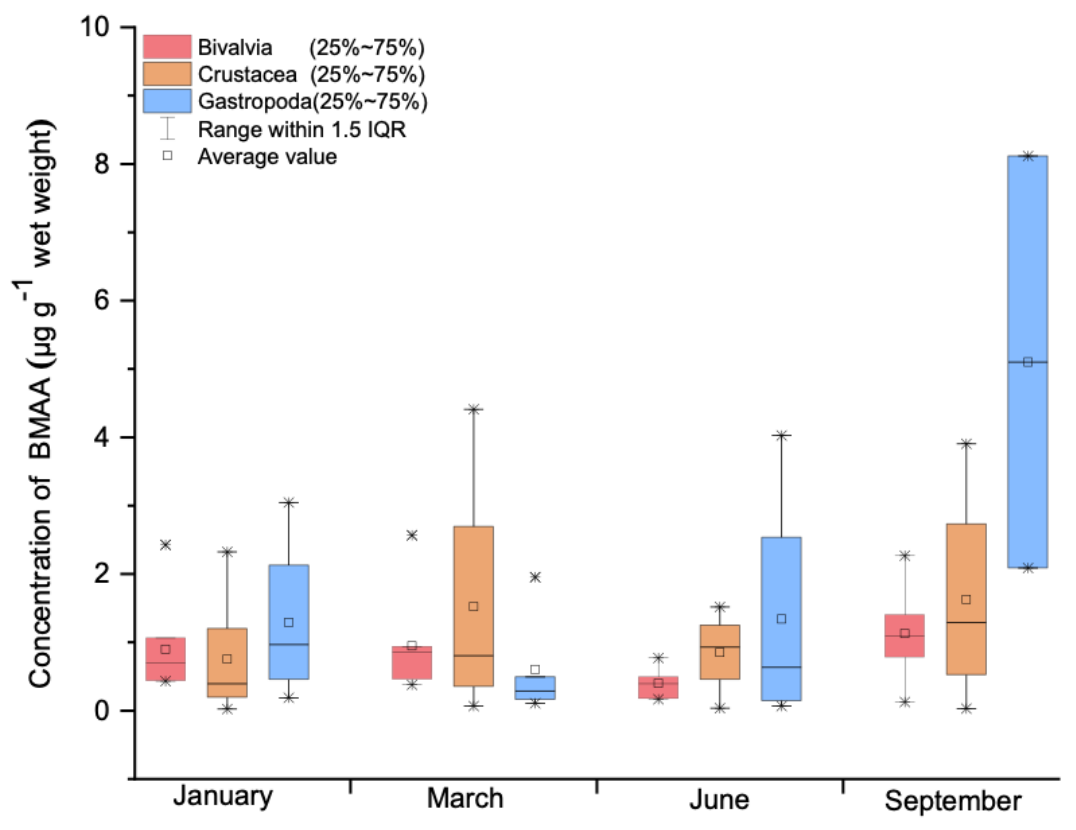

Figure 2: This is a caption

Fig. 3 Concentrations of BMAA in animal samples of mollusks and crustaceans. The unit of BMAA concentration is $\mu \mathrm{g} \mathrm{g}^{-1}$ wet weight of anamials collected from Jiaozhou Bay during four seasons. Boxplots summarizing the concentration of BMAA distributions (total soluble form) in bivalve and gastropod mollusks and crustaceans. Boxes and whiskers cover $50 \%$ and 1.5 times the interquartile range of the data respectively. 


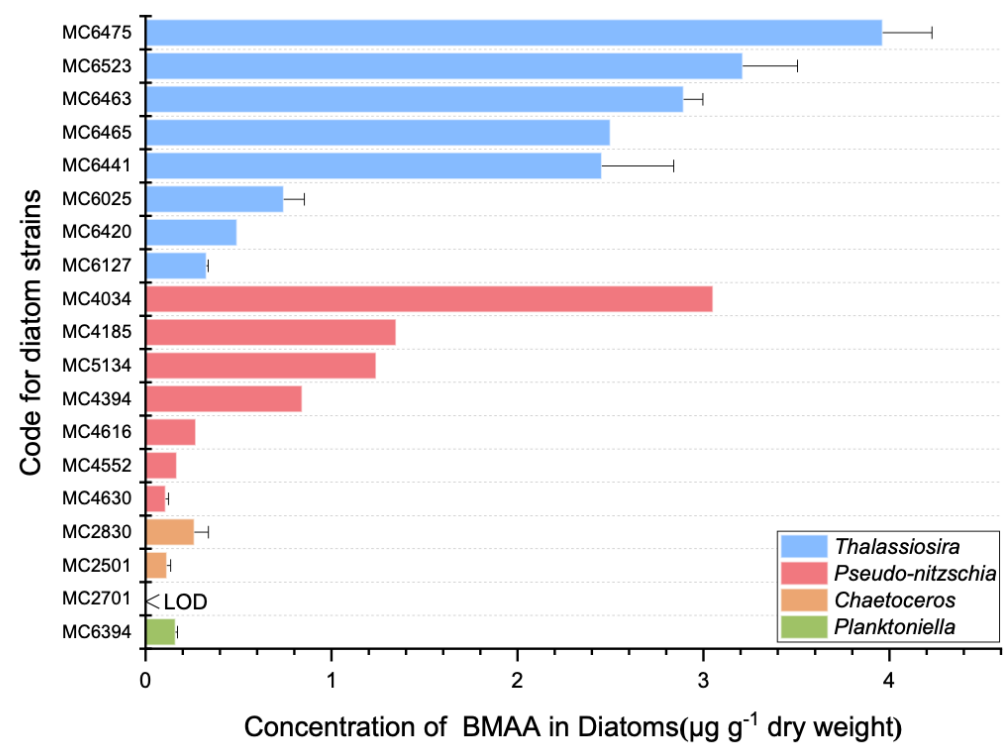

Figure 3: This is a caption

Fig. 4 Comparison of the BMAA production ability by diatoms. Positive results of BMAA were detected in these diatom strains isolated from the coastal area of China and the unit of BMAA concentration is $\mu \mathrm{g} \mathrm{g}^{-1}$ dry weight. The data without error bars were obtained in the first batch of cultures and the wet weight was converted to dry weight. And the data with error bars were obtained in the second batch of cultures, in which each group was set up in three parallel cultures and dry weight was used for microalgal cells.

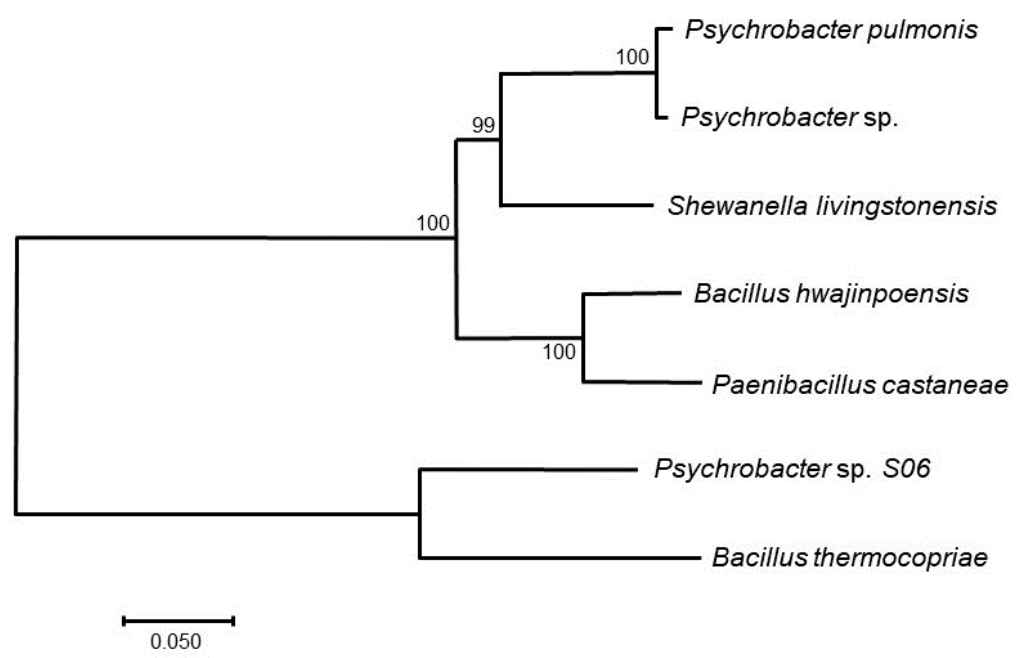

Fig. 5 Phylogeny of seven strains of DAB-producing bacteria isolated from the gut of Neverita didyma. This figure was inferred from partial LSU rDNA sequences using maximum likelihood (ML). Branch lengths are drawn to scale, with the scale bar indicating the number of nucleotide substitutions per site. 


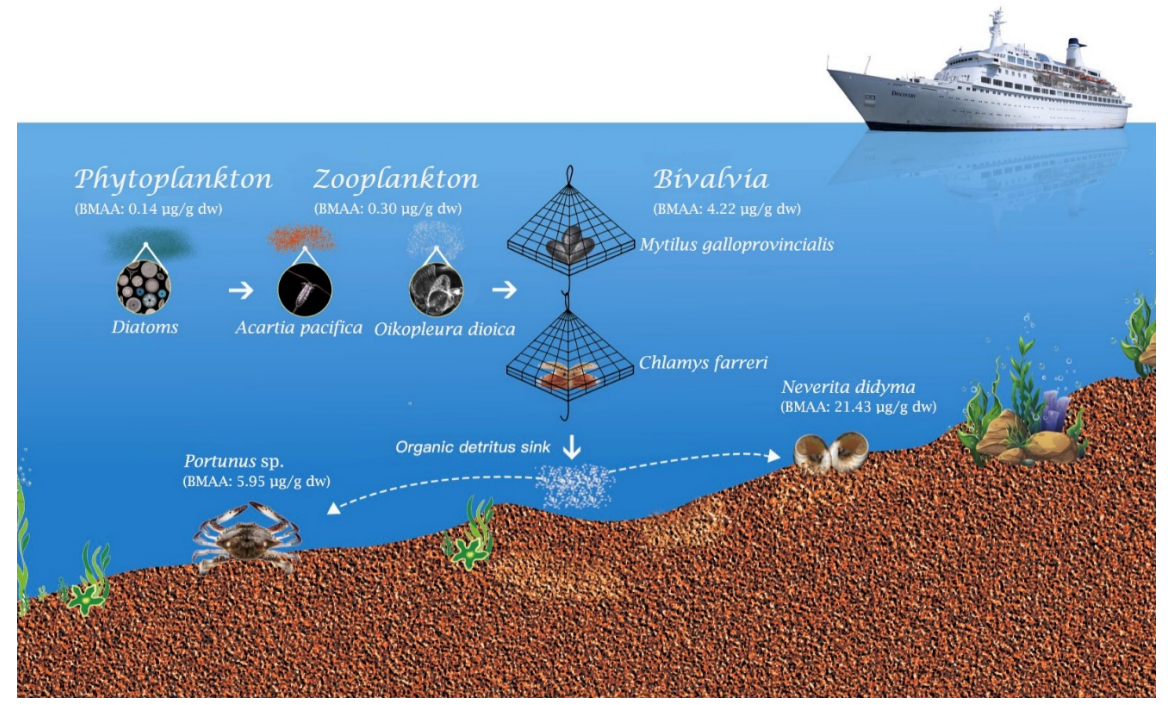

Fig. 6 Schematic diagram of the biomagnification of BMAA along food chains in this study. The arrows indicate the transfer of BMAA between different trophic level. Hanging cages indicate the cultivation of bivalve mollusks along the coast of China. Numbers within parentheses indicate the average BMAA level found in each trophic level, expressed as $\mu \mathrm{g} \mathrm{g}^{-1}$ dry weight.

\section{Supplementary Information}

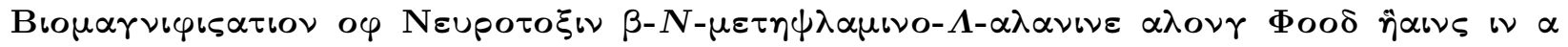

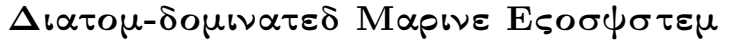

Chao Wang ${ }^{1,2}$, Chen Yan ${ }^{1,2}$, Jiangbing Qiu ${ }^{1,2}$, Chao Liu ${ }^{1,2}$, Yeju Yan ${ }^{1,2}$, Ying Ji ${ }^{1,2}$, Guixiang Wang ${ }^{1,2}$, Hongju Chen ${ }^{1,2}$, Yang $\mathrm{Li}^{3}$, Sandra Anne Banack ${ }^{3}$, Aifeng $\mathrm{Li}^{1,2, *}$

${ }^{1}$ College of Environmental Science and Engineering, Ocean University of China, Qingdao 266100, P.R. China

${ }^{2}$ Key Laboratory of Marine Environment and Ecology, Ocean University of China, Ministry of Education, Qingdao 266100, P.R. China

${ }^{3}$ Guangzhou Key Laboratory of Subtropical Biodiversity and Biomonitoring, Guangdong Provincial Key Laboratory of Healthy and Safe Aquaculture, College of Life Science, South China Normal University, Guangzhou 510631, P.R. China

${ }_{4}^{4}$ Brain Chemistry Labs, Institute for Ethnomedicine, Box 3464, Jackson, WY 83001, USA

\section{Hosted file}

image7.emf available at https://authorea.com/users/333533/articles/459724-migration-andtransformation-behaviors-of-neurotoxin-bmaa-along-food-chains-in-a-diatom-dominatedmarine-ecosystem-in-china

Supplementary Figure 1. LC-MS/MS chromatograms for BMAA, DAB and AEG standards (a, b), extracts of phytoplankton (c, d) and zooplankton (e, f) using HILIC direct analysis (a, c, e) and precolumn AQC-derivatization method (b, d, f). 
Supplementary Figure 2. Percent of diatom and dinoflagellate (\%), and cell density (cell $\mathrm{m}^{-3}$ ) in the phytoplankton net samples collected in (a) January, (b) March, (c) June, and (d) September, from the Jiaozhou Bay.

Supplementary Figure 3. Average concentrations of BMAA in phytoplankton and zooplankton samples collected from 12 sampling stations in Jiaozhou Bay during four seasons.

Supplementary Figure 4. The highest trophic magnification factor (TMF) from phytoplankton to zooplankton at different sampling stations during four seasons. The sampling station $\mathrm{C} 1$ has not been given TMF value because BMAA was not detected in zooplankton in January and not detected in phytoplankton in other seasons. 